\title{
A digestive allergic reaction with hypereosinophilia imputable to docetaxel in a breast cancer patient: a case report
}

\author{
Diaddin Hamdan ${ }^{1,2}$, Christophe Leboeuf ${ }^{2,3}$, Cathy Pereira ${ }^{4}$, Nathalie Jourdan ${ }^{5}$, Laurence Verneuil ${ }^{2,3,6}$, \\ Guilhem Bousquet ${ }^{2,3,7,8,9^{*}}$ and Anne Janin ${ }^{2,3,4^{*}}$
}

\begin{abstract}
Background: Hypereosinophilia, defined by an absolute eosinophil count of more than $1500 / \mathrm{mm} 3$, is rarely observed in patients treated for cancer, and rarely imputable to anti-cancer agents. Drug-induced hypereosinophilia usually appears within a few weeks of the start of treatment and resolves after discontinuation of the medication. We report here a first case of hypereosinophilia with digestive allergic reaction imputable to docetaxel in a woman treated for breast cancer.

Case presentation: This patient, with a history of childhood atopic dermatitis and asthma, underwent surgery for breast lobular carcinoma, followed with chemotherapy including 3 cycles of the FEC100 protocol and 3 cycles of docetaxel. Ten days after the second cycle of docetaxel, she had abdominal pain with diarrhea, which increased after the third cycle of docetaxel at the same dose. The blood eosinophil count increased up to $4685 / \mathrm{mm}^{3}$ at day 92. All biological tests were normal, except elevated seric lgE. The systematic biopsies of the upper and lower digestive tract showed diffuse edema of the lamina propria, lymphocytic infiltrate and CD117-expressing cells both in the epithelium and in the lamina propria. Electron microscopy showed a large number of degranulating mast cells, while the number of tissue eosinophils was small.

The blood eosinophil count decreased after day 96, three months after the last injection of docetaxel. After day 182, the hypereosinophilia and symptoms resolved. This spontaneous evolution, the history of atopic dermatitis and asthma, and the negativity of all biological tests performed led us to hypothesize a diagnosis of a systemic digestive Type 1 drug-induced hypersensitivity reaction. Using two validated pharmacovigilance scales, we found that docetaxel had the highest imputability score compared to the other drugs.

Conclusion: Recognition of allergic reactions imputable to docetaxel is important because it requires the drug to be discontinued. In the difficult setting of anti-cancer treatment, if reintroduction of the drug is needed, a close collaboration between oncologists, gastroenterologists and allergologists is required.
\end{abstract}

Keywords: Docetaxel, Allergic reaction, Hypereosinophilia, Digestive tract

\section{Background}

Hypereosinophilia, defined by an absolute eosinophil count of more than $1500 / \mathrm{mm} 3$, is rarely observed in patients treated for cancer [1]. The main drugs responsible for hyperesosinophilia are penicillins, cephalosporins, sulfas, quinolones, and non-steroid anti-inflammatory

\footnotetext{
* Correspondence: guilhem.bousquet@aphp.fr; anne.janin1165@gmail.com Anne Janin and Guilhem Bousquet are co-senior authors

${ }^{2}$ U1165, Université Paris7, Inserm, Hôpital Saint-Louis, Paris F-75010, France

Full list of author information is available at the end of the article
}

drugs [2], but hypereosinophilia is rarely imputable to anti-cancer agents (see Additional file 1: Methods M1 for details on search strategy, and Additional file 2: Table S1 for the results of the systematic literature search). Drug-induced blood hypereosinophilia usually appears within a 2 to 10 weeks of the start of treatment and resolves after discontinuation of the medication (Additional file 2: Table S1). 
Blood hypereosinophilia is associated with potentially lethal clinical complications, mainly cardiac, cutaneous, neurologic or pulmonary [3].

We report here a first case of hypereosinophilia with systemic digestive allergic reaction imputable to docetaxel in a woman treated for a localized breast cancer.

\section{Case presentation}

This 40-years-old Caucasian woman, with a history of childhood atopic dermatitis and asthma, underwent surgery for breast lobular carcinoma of $30 \mathrm{~mm}$, histological grade III, expressing estrogen and progesterone receptors, with no lymph node involvement. In accordance with French guidelines, she received post-surgery chemotherapy including 3 cycles of the FEC100 protocol - 5FluoroUracile $500 \mathrm{mg} / \mathrm{m}^{2} /$ cycle (Accord, France), epirubicin $100 \mathrm{mg} / \mathrm{m}^{2} /$ cycle (Mylan, France) cyclophosphamid $500 \mathrm{mg} / \mathrm{m}^{2} /$ cycle (Baxter, France) - and 3 cycles of docetaxel $100 \mathrm{mg} / \mathrm{m}^{2} /$ cycle (Docetaxel Kabi @) (ATC-Code L01CD02), Fresenius, France).

Ten days after the second cycle of docetaxel, she had abdominal pain with diarrhea ( $2-5$ stools/day), which increased after the third cycle of docetaxel at the same dose. The eosinophil count was $2001 / \mathrm{mm}^{3}$ at day 60 , and $4685 / \mathrm{mm}^{3}$ at day 92 (Fig. 1).

Systematic biological tests and digestive biopsies were performed at day 92. No parasitological, bacteriological, virological, immunological or hematological cause was found; only seric IgE were elevated (Additional file 3: Table S2). The systematic biopsies of the upper and lower digestive tract showed similarities in the gut and colonic biopsies. All four biopsies had diffuse edema of the lamina propria, lymphocytic infiltrate and CD117- expressing cells both in the epithelium and in the lamina propria (see Additional file 1: Methods and Fig. 2a). We used electron microscopy, and anti-tryptase and antieosinophil peroxidase antibodies to differentiate and count mast cells and eosinophils in the two compartments (see Additional file 1: Methods and Fig. 2b, c, and Tables 1, 2). The diagnosis of eosinophilic gastroenteritis was excluded because of the small number of tissue eosinophils [4]. Electron microscopy showed a large number of degranulating mast cells. No sign of thrombosis, necrosis or vascular-wall damage was found.

The blood eosinophil count decreased after day 96, three months after the last injection of docetaxel. Despite 4 months of hypereosinophilia, we did not detect cardiac, respiratory, liver or renal complications.

After day 182, the hypereosinophilia and symptoms resolved. This spontaneous evolution, the history of atopic dermatitis and asthma, and the negativity of all biological tests performed led us to hypothesize a diagnosis of a drug-induced hypersensitivity reaction (HSR). Using two validated pharmacovigilance scales, we found that docetaxel had the highest imputability score compared to the other drugs (Additional file 4: Figure S1 and Table 3).

Docetaxel, a semi-synthetic taxoid that inhibits depolymerization of microtubules, is currently approved for the treatment of breast, lung and prostate cancers. The most frequent adverse effects of docetaxel are hematological (pancytopenia) and digestive. Diarrhea is reported in 30 to $60 \%$ of patients (Additional file 5: Table S3), often associated with severe oral mucositis. These toxic lesions (Type A adverse drug reaction) are predictable, dose-dependent reactions linked to prolonged

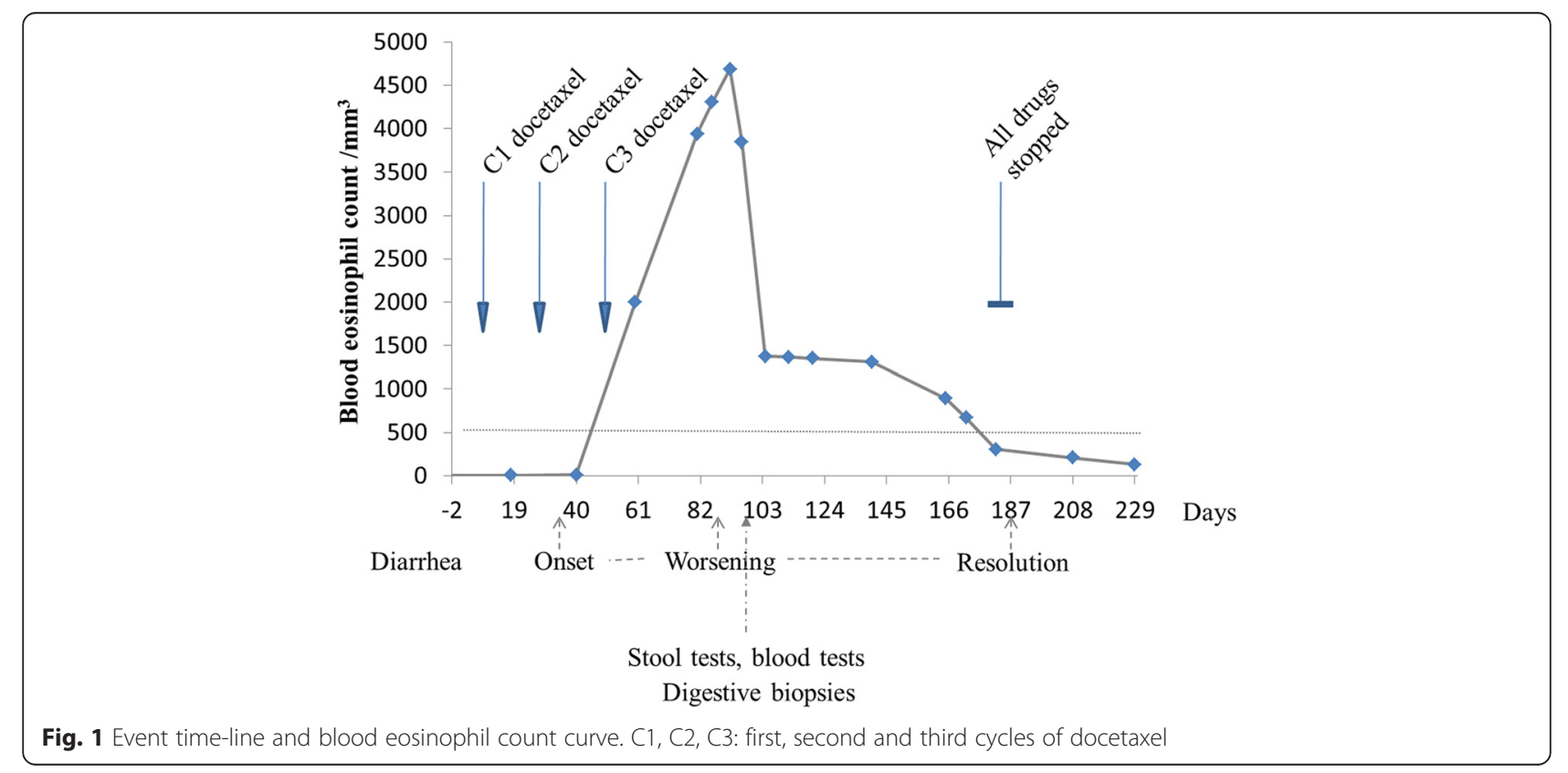



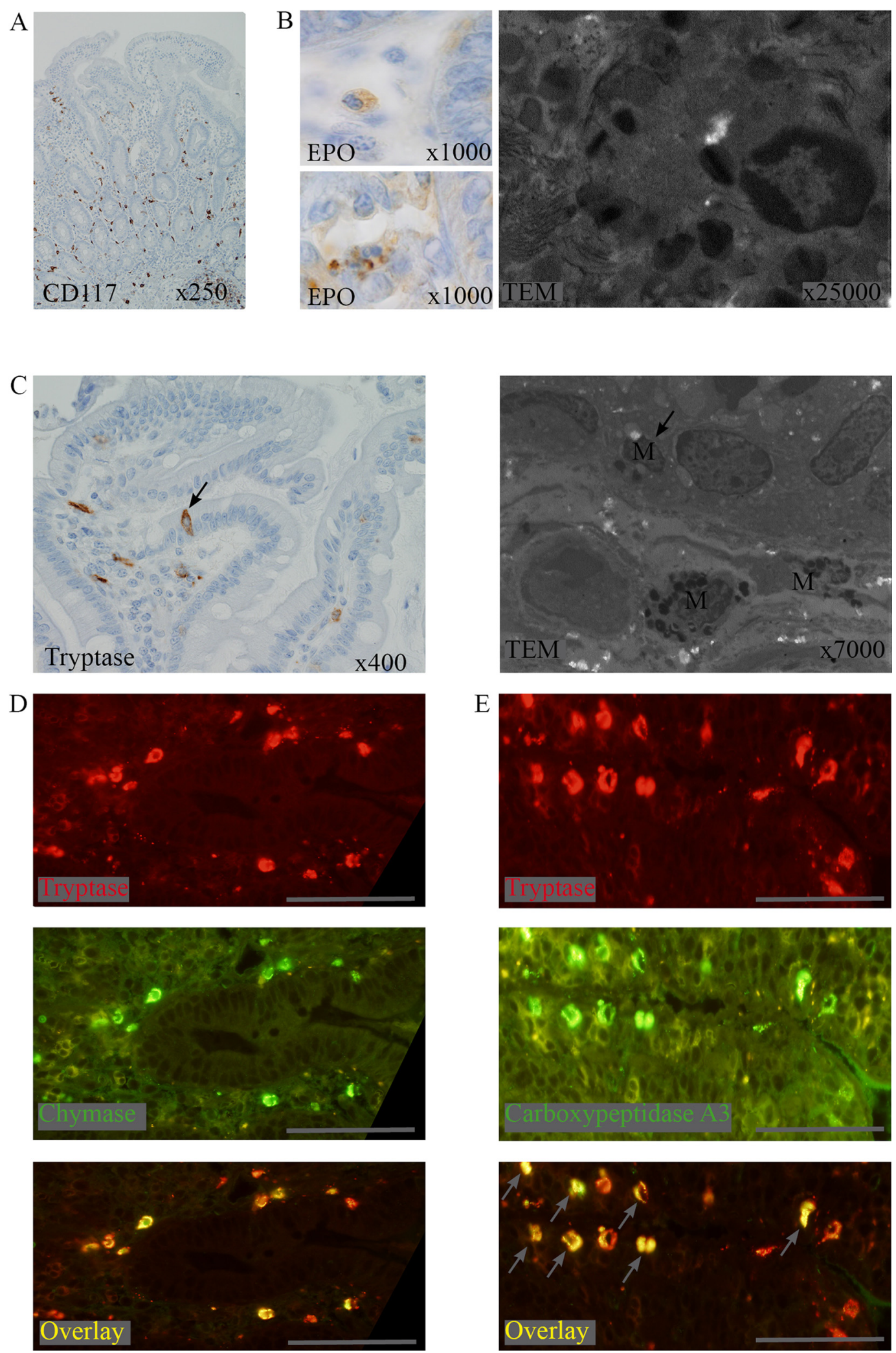

Fig. 2 (See legend on next page.) 
(See figure on previous page.)

Fig. 2 Characterization of cell infiltrates in the epithelium and lamina propria of the duodenum. Duodenal biopsies with CD117-expressing cells (a), which include eosinophils expressing eosinophil peroxidase (EPO) and containing specific granules (b); and mast cells (M) expressing tryptase and located in the lamina propria and epithelium (arrows, c). Mast cells in the lamina propria coexpress tryptase and chymase (d). Mast cells in the epithelium (arrows) coexpress tryptase and carboxypeptidase A3 (e)

Table 1 Inflammatory cell counts in gut and colon

\begin{tabular}{llll}
\hline Digestive samples & Epithelium & & \\
\cline { 2 - 4 } & Lymphocytes & Mast cells & Eosinophils \\
\hline Duodenum & $10.2 \pm 4.1$ & $4.4 \pm 0.8$ & $2.4 \pm 0.7$ \\
Jejunum & $12.4 \pm 3.1$ & $2.3 \pm 0.5$ & $1.2 \pm 0.5$ \\
Right colon & $7.8 \pm 1.2$ & $2.5 \pm 0.3$ & $0.4 \pm 0.1$ \\
Left colon & $8.4 \pm 0.9$ & $3.2 \pm 1.1$ & $1.3 \pm 0.4$ \\
\hline
\end{tabular}

Table 2 Inflammatory cell counts in gut and colon

\begin{tabular}{lllll}
\hline Digestive samples & Lamina propria & & & \\
\cline { 2 - 5 } & Lymphocytes & Plasma cells & Mast cells & \\
\hline Duodenum & $66.3 \pm 9.2$ & $28.7 \pm 5.1$ & $12.3 \pm 2.1$ & Eosinophils \\
Jejunum & $70.8 \pm 10.1$ & $26.4 \pm 4.5$ & $9.6 \pm 2.5$ & $4.8 \pm 0.9$ \\
Right colon & $65.5 \pm 7.5$ & $27.9 \pm 5.3$ & $8.2 \pm 1.6$ & $3.5 \pm 0.6$ \\
Left colon & $58.0 \pm 6.7$ & $24.3 \pm 3.9$ & $9.5 \pm 1.0$ & $2.0 \pm 0.3$ \\
\hline
\end{tabular}

Table 3 Drug imputability scores

\begin{tabular}{|c|c|c|c|c|c|}
\hline \multirow[b]{2}{*}{ Drugs } & \multirow{2}{*}{$\begin{array}{l}\text { Adverse Drug Reaction probability scale }{ }^{a} \\
\text { Score }\end{array}$} & \multicolumn{4}{|c|}{ French imputability score ${ }^{b}$} \\
\hline & & IS & $C$ & $S$ & Intrinsic imputability \\
\hline Docetaxel & 7 & 2 & 3 & 3 & 16 \\
\hline Ondansetrone & 4 & 2 & 1 & 2 & 12 \\
\hline Diosmectite & -1 & 2 & 0 & 1 & 10 \\
\hline Paracetamol & -1 & 2 & 0 & 1 & 10 \\
\hline Fluconazole & -1 & 2 & 0 & 1 & 10 \\
\hline Racecadotril & -1 & 2 & 0 & 1 & 10 \\
\hline Metoclopramide & -1 & 2 & 0 & 1 & 10 \\
\hline Omeprazole & -1 & 2 & 0 & 1 & 10 \\
\hline Phloroglucinol & -1 & 2 & 0 & 1 & 10 \\
\hline Prednisone & -1 & 2 & 0 & 1 & 10 \\
\hline
\end{tabular}


or daily exposure to the drug [5], whereas HSR under docetaxel treatment (Type B immunologically-mediated adverse drug reaction according to Gell-Coombs classification, ref [5]) is dose-independent [6]. Severe HSR to docetaxel is observed in $3 \%$ to $7.7 \%$ of patients (Additional file 3: Table S2, and Reference [7] for review). Lethal druginduced HSR has been reported in $0.05 \%$ of 36,983 pati ents [8].

In the case of our patient who developed diarrhea and severe hypereosinophilia after the second injection of docetaxel, the two available pharmacovigilance scales concluded to docetaxel imputability. Since our patient had neither pancytopenia nor oral mucositis, and since docetaxel had not been administered daily or for a prolonged period, we concluded that the diarrhea was not related to a classic digestive toxicity but to Type B immune-mediated adverse drug reaction. The digestive symptoms occurred after the second injection of docetaxel, and the blood hypereosinophilia after the third injection concomitantly with elevated seric IgE. The digestive biopsies showed that the whole digestive tract was involved, with edema, large numbers of mast cells, and few eosinophils. Under electron microscopy, both eosinophils and mast cells were degranulated. Overall, these findings are in favor of a systemic digestive Type 1 hypersensitivity reaction.

Using specific antibodies (see Additional file 1: Methods), we showed that mast cells and eosinophils were distributed within the epithelium and the lamina propria. In bronchial biopsies of mild to moderate $\mathrm{T}_{\mathrm{H}}$ 2-high asthma associated with blood eosinophilia [9], intra-epithelial mast cells coexpressed tryptase and carboxypeptidase A3, whereas mast cells of the lamina propria co-expressed tryptase and chymase. We also found these differential enzymatic coexpressions in epithelial and lamina propria mast cells in the digestive biopsies of our patient (Fig. 2d, e). In asthmatic and atopic patients, a similar immunoreactivity for IL-3, IL-5 and GM-CSF has also been found in bronchial and gut mucosa [10].

\section{Conclusion}

We here report a case of severe HSR with hypereosinophilia imputable to docetaxel. While this condition is rare, it is important to recognize it, since it requires the drug to be discontinued. Since blood hypereosinophilia over $1500 / \mu \mathrm{L}$ and lasting more than 1 month entails a risk of major organ dysfunction $[1,11]$, including death through cardiac failure [12], therapy discontinuation can be recommended if these conditions are observed. In the field of adverse reactions to anti-cancer drugs, this is particularly relevant for docetaxel treatment, which can be prolonged for several months in case of good response for metastatic breast, lung or prostate cancers. If reintroduction of this anti-cancer agent is needed, a close collaboration between oncologists, gastroenterologists and allergologists is required.

\section{Consent}

Written informed consent was obtained from the patient for publication of this Case report and any accompanying images. A copy of the written consent is available for review by the Editor of this journal.

\section{Additional files}

Additional file 1: Methods M1. (DOCX $18 \mathrm{~kb}$ )

Additional file 2: Table S1. Published cases of blood hypereosinophilia imputable to anti-cancer drugs. (DOCX $15 \mathrm{~kb}$ )

Additional file 3: Table S2. Laboratory tests (DOCX $18 \mathrm{~kb}$ )

Additional file 4: Figure S1. Drug intake between day 0 (D0) and D182. D0 is the time of the first injection of docetaxel and D182 the time when all drugs were stopped. For drugs administered continuously like omeprazole, the period of drug intake is symbolized by a straight line between the first day and the last day of treatment. (JPG 81 kb)

Additional file 5: Table S3. Adverse events in clinical trials using docetaxel monotherapy. (DOCX $16 \mathrm{~kb}$ )

Abbreviations

HSR: hypersensitivity reaction.

\section{Competing interests}

The authors do not have any conflict of interest

\section{Authors' contributions}

$\mathrm{DH}, \mathrm{GB}$ and AJ conceived and designed the study; DH and GB collected clinical data. CP performed electron microscopy. CL performed immunostainings. DH, $C L, N J, G B$ and $A J$ did analysis and interpretation of data. DH, GB and AJ wrote the manuscript. LV made a critical revision of the manuscript. All authors read and approved the final version of the manuscript.

\section{Acknowledgements}

This work was supported by University-Paris-Diderot, INSERM. We thank Massimiliano Orri for the algorithm design of literature search. Ms Angela Swaine reviewed the English language.

\section{Author details}

${ }^{1}$ Centre Hospitalier de Marne-la-Vallée, Service d'Oncologie Médicale, Jossigny F-77600, France. ²U1165, Université Paris7, Inserm, Hôpital Saint-Louis, Paris F-75010, France. ${ }^{3}$ Université Paris Diderot, Sorbonne Paris Cité, Laboratoire de Pathologie, UMR-S 1165, F-75010 Paris, France. ${ }^{4}$ AP-HP-Hôpital Saint-Louis, Laboratoire de Pathologie, Paris F-75010, France. ${ }^{5}$ AP-HP-Hôpital Saint-Louis, Pharmacie, Paris F-75010, France. ${ }^{6}$ Université de Caen Basse-Normandie, Medical School, Caen F-14000, France.

${ }^{7}$ AP-HP-Hôpital Avicenne, Service d'Oncologie Médicale, Bobigny F-93008, France. ${ }^{8}$ Université Paris 13, Leonard de Vinci, Villetaneuse F-93430, France. ${ }^{9} U 1165,1$ avenue Vellefaux, Paris F-75010, France.

Received: 4 September 2015 Accepted: 14 December 2015 Published online: 21 December 2015

References

1. Helbig G. Advances in the diagnosis and treatment of eosinophilia. Curr Opin Hematol. 2014;21(1):3-7. doi:10.1097/MOH.0000000000000011.

2. Nutman TB. Evaluation and differential diagnosis of marked, persistent eosinophilia. Immunol Allergy Clin North Am. 2007;27(3):529-49. doi:10. 1016/j.iac.2007.07.008.

3. Weller PF, Bubley GJ. The idiopathic hypereosinophilic syndrome. Blood. 1994;83(10):2759-79.

4. Desreumaux P, Bloget F, Seguy D, Capron M, Cortot A, Colombel JF, et al. Interleukin 3, granulocyte-macrophage colony-stimulating factor, and 
interleukin 5 in eosinophilic gastroenteritis. Gastroenterology. 1996;110(3): 768-74.

5. Rive CM, Bourke J, Phillips EJ. Testing for drug hypersensitivity syndromes. Clin Biochem Rev. 2013;34(1):15-38.

6. Pazdur R, Newman RA, Newman BM, Fuentes A, Benvenuto J, Bready B, et al. Phase I trial of Taxotere: five-day schedule. J Natl Cancer Inst. 1992; 84(23):1781-8.

7. Picard M, Castells MC. Re-visiting hypersensitivity reactions to taxanes: a comprehensive review. Clin Rev Allergy Immunol. 2015;49(2):177-91. doi:10. 1007/s12016-014-8416-0.

8. Kadoyama K, Kuwahara A, Yamamori M, Brown JB, Sakaeda T, Okuno Y. Hypersensitivity reactions to anticancer agents: data mining of the public version of the FDA adverse event reporting system, AERS. J Exp Clin Cancer Res. 2011;30:93. doi:10.1186/1756-9966-30-93.

9. Dougherty RH, Sidhu SS, Raman K, Solon M, Solberg OD, Caughey GH, et al. Accumulation of intraepithelial mast cells with a unique protease phenotype in T(H)2-high asthma. J Allergy Clin Immunol. 2010;125(5):1046-53 e8. doi:10.1016/J. jaci.2010.03.003.

10. Wallaert B, Desreumaux P, Copin MC, Tillie I, Benard A, Colombel JF, et al. Immunoreactivity for interleukin 3 and 5 and granulocyte/macrophage colony-stimulating factor of intestinal mucosa in bronchial asthma. J Exp Med. 1995;182(6):1897-904.

11. Valent P, Klion AD, Horny HP, Roufosse F, Gotlib J, Weller PF, et al. Contemporary consensus proposal on criteria and classification of eosinophilic disorders and related syndromes. J Allergy Clin Immunol. 2012;130(3):607-12. doi:10.1016/j.jaci.2012.02.019. e9.

12. Sohn KH, Song WJ, Kim BK, Kang MK, Lee SY, Suh JW, et al. Eosinophilic myocarditis: case series and literature review. Asia Pacific Allergy. 2015;5(2):123-7. doi:10.5415/apallergy.2015.5.2.123.

Submit your next manuscript to BioMed Central and we will help you at every step:

- We accept pre-submission inquiries

- Our selector tool helps you to find the most relevant journal

- We provide round the clock customer support

- Convenient online submission

- Thorough peer review

- Inclusion in PubMed and all major indexing services

- Maximum visibility for your research

Submit your manuscript at www.biomedcentral.com/submit
Biomed Central 